\title{
Editorial
}

\section{Use of ICT by Members of Parliament}

Members of parliament (MPs) have, like the majority of citizens in the European countries, increasingly taken up the use of information- and communication technology (ICT) as a part of their everyday work routines: in their information gathering, in dealings with parliamentary and party staff, in contacts with voters and citizens, organised interest groups, the media, etc. This use of ICT is likely to have an effect on both the volume and content of information- and communication flows between the MP and his/her political environment, and possibly also on the different roles of the MP.

However now little research has been carried out in this field, and not much is known about the changes that the different uses of ICT have brought about in the work routines, roles, political agenda setting and decision making processes in which MPs are involved. For this reason a group of European researchers under the auspices of COST A14, a European research network on "Government and Democracy in the Information Age" funded by the European Union Co-operation on Science and Technology, ${ }^{1}$ decided to undertake a comparative study of the use of ICT by MPs. A common survey questionnaire was developed for surveys including all MPs in the countries, which decided to join the Parliamentary project. These countries were Austria, Norway, Portugal, the Netherlands and Denmark, where surveys were done in 2001, followed by Scotland and Germany where surveys were done in 2002. Also, a survey was conducted in Switzerland, using a similar but not identical survey format. In some of the countries a number of follow-up qualitative interviews with MPs were done in order to elaborate on answers and correlations that seemed unclear or contradictory in the survey responses, and to bring in perspectives that might have been neglected in the surveys. Also, attempts were made to have surveys conducted in France and the UK, in order to bring in more of the bigger European countries in the study. Unfortunately, these attempts were unsuccessful.

The results of these surveys are presented in the different articles in this volume. In order to bring forward the comparative perspective the results are not presented country by country. Instead the articles are organised thematically, apart from an introductory article by Hoff, Kleinsteuber and Fries giving an overall presentation of research questions, methodology, data and some of the main results. Thus, in the second article, Filzmaier, Stainer-Hämmerle and Snellen elaborate on the institutional framework of the project, spelling out the internal and external factors that could be seen to influence the appropriation of ICTs by MPs. Narrowing the analyses down to a comparison between Austria, the Netherlands and Denmark, different modes of utilisation of ICTs are analysed. It is concluded that the Internet is used more frequently for internal communication (with party and parliamentary staff) than for external communication (with voters, lobby groups, etc.), and that political campaigning and marketing on the Internet is not very common and has a low status, but might be on the rise. Concerning differences between the three countries in the volume and type of ICTs used, such factors as the structure of the

\footnotetext{
${ }^{1}$ COST A14 ran from 1998 to 2003, involved around 70 researchers from 16 different European countries, and was funded by approximately 300.000 Euro.
} 
parliament (single or bicameral), the type of election system (party or personalised representation), and the character of the media system (degree of monopolisation) are seen to be of importance in explaining these differences.

In the third article, Cardoso, Cunha and Nascimento take a closer look at ICT as a method of internal and external communication. Focusing more on the content of political communication, it is demonstrated that MPs still favour traditional media (television, radio and newspapers) for political communication, and that insofar as the Internet is used for political campaigning the use is largely dependent on the political party of the MPs and the party's electoral strategies, thereby limiting the MPs' individual initiatives. The article compares all seven countries, but does so from a Portuguese perspective, also drawing on interviews with Portuguese MPs. It is shown that at least among these MPs there is a strong resistance to seriously considering public participation through ICTs.

Elvebakk, in her article, focuses on the importance of competence and experience with ICTs for the ways in which MPs choose to use ICT in his/her parliamentary work. She also brings in all seven countries in her analysis, but with a bias towards the Northern European countries, having the highest rate of diffusion of ICTs among their populations, and the biggest use of this technology among their MPs. Her results show that there are few indications that MPs seek to reinvent or reinterpret their public role by means of the Internet. However, the fact that MPs who have been exposed to Internet technologies prior to becoming MPs are more committed users may suggest that ICTs will be used more widely in the future, as the present generation of parliamentarians is replaced. Furthermore, her findings indicate that the different levels of usage of ICTs does not so much reflect skills and experience with the Internet as they reflect culture, habit and tradition. And as Parliaments are by their very nature conservative institutions we should not expect to see the seeds of change sown there.

In his article, Hoff carries out an analysis of the attitudes of MPs towards the democratic potentials of ICT. He chooses four countries for comparison based on the diffusion of ICT in the respective countries. The countries chosen are Denmark, Norway, Austria and Portugal, and in the analyses carried out it is demonstrated firstly, that there is a very big and homogenous belief in the positive democratic potentials of ICT across the countries, and secondly that the degree of involvement with ICT is of greater importance for the evaluation of the democratic potentials of ICT than more "traditional" background factors such as age, gender and party affiliation. A possible explanation of the first finding is that MPs, as a part of an European elite, have internalised or are themselves actively taking part in creating a discourse about the positive effects of ICT; a discourse which is also cleverly transmitted by such organisations as the EU and OECD.

The Scottish Parliament and Scottish MPs represent a very interesting case when it comes to the use of ICT. (Re-)established in 1999, and from the beginning resourced with a high level of ICT support, it represents a prime example of a modern, "wired" parliament. In their article, Smith and Webster show that this is reflected in both the use of ICT as well as in the attitudes of Scottish members of parliaments' (MSPs) attitudes towards the democratic potentials of these new technologies. Thus, both the use of ICTs as well as the positive attitudes surpasses those of all other European MPs in our studies. Another novelty in a UK context concerning the Scottish Parliament is its incorporation of a new electoral system, electing MSPs both directly through constituencies, and via regional party lists. The MSPs elected via the party list system have a whole new relationship with their electorate than previously experienced in the UK, and they were therefore expected to be particularly keen on exploiting the new technologies in order to assert their legitimacy. However, Smith and Webster's analysis shows the opposite to be true: MSPs elected through traditional constituencies have higher levels of use and also more positive views on the potential of the technology than those elected via party lists. 
Have you ever heard about the "Röstigraben"? If not, Chappelet in his article brings this linguistic and cultural border between French-speaking and German-speaking Switzerland to your attention by forcefully demonstrating its relevance for the appropriation of ICT by Swiss MPs. Thus, there seems to be a significant delay among the French and Italian speaking Swiss MPs in picking up almost all aspects of ICT as compared to their German speaking colleagues. This difference is also reflected in the attitudes towards the new technologies. Furthermore, also political culture is of importance as Socialist and Green MPs are seen to be the "champions" of Internet use in the Swiss Parliament.

With its almost forty years of experience in utilising ICT the US Congress serves as a very good point of reference for the more recent European experiences, and also as a case from which some lessons might be learned in terms of the impact of ICT on the politics and procedures of MPs and parliaments. Thus, in the closing article Stephen Frantzich shows that even though ICT has brought about some "revolutions" in terms of for example a decentralisation and a flatting of organisational structure in congressional offices, and an increased democratisation and ability to hold decision-makers responsible for past actions, the inherent characteristics of the electoral system, and of Congressional procedures decisively shape members of congress' use of ICT.

Critics might speculate why we have taken on the analysis of such a peculiar minority as MPs in a number of rather randomly chosen European countries. Isn't it so that the power of national parliaments and the importance of MPs have been severely diminished by the "hollowing out of the state", and by the "explosion of politics", establishing a huge number of new political arenas in a complex system of global multilevel governance?

We agree that with the advance of globalisation, and with the increased European economic and political collaboration, powers have indeed been removed from national parliaments (even though power games at this level is not adequately analysed as zero-sum games), and therefore nation states today are probably best seen as strategic actors among many other strategic actors on a global scene which appears more and more like a "new medieval order" [2]. None the less we will maintain that national parliaments are still very special institutions, as they are the sole institutions that can legitimately tax their populations, declare war, enforce laws within the national territory etc. Considerable and special powers are therefore still embedded in national parliaments. Also, national parliaments are deeply embedded in national political culture, often being an important part of the nation building process and thus of national history. So, even though national parliaments in Europe, as well as elsewhere, have been markedly reconfigured in terms of powers and tasks during the last 10-20, years they are still crucial nodes in the network society connecting global and transnational centres of political decision making with national and subnational/regional political centres [1]. At the national level the "mediatization" of politics, and the increased independence (from the state) of the media has meant that the political agenda (both day-to-day and long term) is set in an interplay between the parliamentary arena, the corporate arena and the discursive arena (the media). Parliaments (MPs) therefore have to maintain and develop their horizontal information and communication flows with these other arenas. However, they also have to maintain and develop their vertical information and communication flows with voters and constituencies in order to develop and legitimise policies. In this issue we start the analysis of the digitalisation of these information and communication flows, and touch upon questions of the political and democratic importance of this digitalisation. However, much research is still needed in order to properly understand the role of parliaments/MPs as crucial nodes in the network society.

There are three specific areas of research that call for attention. Firstly, we know too little about what citizens want from their elected representatives. Is there a public demand for frequent, interactive communicative between MPs and the public? If so, does the demand come from the general public 
or from those who are already the most articulate, resourced and connected to the political system? Secondly, it is probably too early to know whether politicians' use of ICT increases the electoral benefits of incumbency. In theory, one might expect it to be the case that MPs who possess well-organised offices and databases of their constituents will have an advantage over competitors who lack these benefits. Will the political use of ICT come to be seen as an electoral advantage? Thirdly, there has not been much research conducted on the relationship between MPs and their parties. How far are ICT used to discipline elected representatives and constrain their capacity to organise out of line with their political leaderships? Or, if parties fail to utilise ICT in appropriate ways, might this open up opportunities for 'independent' outsiders, perhaps from new social movements, who might challenge the organisational monopolies of parties. Finally, there is a need to explore the risks for MPs in using ICT, whether in placing certain material on their web sites, having electronic records hacked into or failing to cope with the 'overload' produced by new forms of communication. These are all subjects for future research.

Finally, we would like to thank first of all the European Co-operation on Science and Technology (COST) for enabling the group of researchers behind this special issue to meet a number of times during the last five years in order to plan and discuss the research being presented here. We would also like to thank different national research councils, and other funding agencies, among these the Danish Power Study (Danish Parliament) for their support of parts of the research undertaken, and their support for a conference in Copenhagen in January 2003 on "Democratic Governance and ICT", allowing the authors to lay the final plan for this issue of Information Polity. Lastly, we should not forget the Oxford Internet Institute, which set up a conference on "Political Representation in the Digital Age" in October 2003 allowing some of the editors to meet and take care of the last details.

Copenhagen, Oxford, Klagenfurt and Lisbon, April 2004

Jens Hoff

University of Copenhagen, Denmark

Stephen Coleman

Oxford Internet Institute, UK

Peter Filzmaier

University of Klagenfurt, Austria

Gustavo Cardoso

I.S.C.T.E., Lisbon, Portugal

\section{References}

[1] M. Castells, The Internet Galaxy, Oxford University Press, Oxford, 2002.

[2] D. Held and A. McGrew eds, Governing Globalization, Polity Press, Cambridge, 2002. 